\title{
Potential of acetamiprid to induce testicular oxidative stress, apoptosis and hormonal disturbance in male albino Wistar rats
}

\author{
ahmed ahmed ${ }^{1}$ \\ ${ }^{1}$ Tanta University
}

June 18, 2020

\begin{abstract}
Introduction, acetamiprid (AMP) is an insecticide that can affect human health as it is easily absorbed through gastrointestinal mucosa inducing erectile dysfunction and reduction of total sperm count. Many research studies had examined the effect of AMP on different body organs while this study was designed to study the underlying mechanisms of AMP associated reproductive toxicity. Material and methods, 40 male albino Wistar rats were divided into four groups. Control (C) group, received vehicle. $40 \mathrm{mg}$ dose (40D), $30 \mathrm{mg}$ dose (30D) and $10 \mathrm{mg}$ dose (10D) groups received $40 \mathrm{mg} / \mathrm{kg}$ b.w., $30 \mathrm{mg} / \mathrm{kg}$ b.w., $10 \mathrm{mg} / \mathrm{kg}$ b.w. of AMP by oral gavage daily for 90 days. Results, sperm counts were significantly decreased in AMP treated groups with an increased count of flattened headed sperms in 40D-group. Plasma and testicular tissue GSH and TAS levels were significantly decreased while MDA and TOS levels were significantly increased after AMP administration in a dose dependent manner while plasma LH, FSH, GnRH and INHB levels were significantly increased. Seminiferous tubules basement membrane showed irregularities in 40D and 30D groups with a decrease in spermatogenic cells number. The testicular proliferative index was decreased associated with an increase in apoptotic index in AMP treated groups. Conclusion, AMP oral administration in a dose $10-40 \mathrm{mg} / \mathrm{kg}$ b.w. to male albino Wistar rats was found to possess an oxidative stress and apoptotic impact on the reproductive system which could be reflected on the occupational health precautions.
\end{abstract}

\section{Key words}

Acetamiprid; Oxidative stress; Apoptosis; Hormonal disturbance; Reproductive system

\section{Introduction}

Acetamiprid (AMP) or Assail ${ }^{\circledR}$, is a commonly used odorless neonicotinoid insecticide introduced in 1990s with chemical formula $\mathrm{C}_{10} \mathrm{H}_{11} \mathrm{ClN}_{4}$ (1). It is used for protection vegetables, fruits, cherry, grapes and cotton against sucking type insects (Thysanoptera, Hemiptera) (2). It is a nicotinic agonist acting through its ability to bind with nicotinic acetylcholine receptor in brain, spinal cord and neuromuscular junctions of insects (3). It accumulate in apples, eggplant, cabbage and carrot and has a potential to contaminate water which could affect the human health and also it is classified as a weak human carcinogen (4). If AMP is accidentally ingested, it could be readily absorbed through gastrointestinal mucosa reaching maximum blood concentration within two hours then accumulate in either parenchymatous (liver, kidney) or endocrinal (thyroid, suprarenal) organs. It was reported that AMP possess a toxic effect on nervous and respiratory systems (5).

Human ingestion of AMP could result in an acute poisoning condition that could be recovered within fortyeight hours (6), while its chronic exposure reported to induce reproductive toxicity manifested in the form of erectile dysfunction and reduction of total sperm count (TSC) (7). Although many research studies had examined the effect of AMP on different body organs (8), a true need to study the specific effect (and underlying mechanisms) of AMP on male reproductive organs is rising on the horizon. So, this study was designed accordingly. 


\section{Material and methods}

Chemicals:

Acetamiprid were purchased from Sino pharm Chemical Reagent Co., Ltd., China and dissolved in 0.5\% methylcellulose.

Animals:

40 males Albino Wistar rats were used. Rats' average weight and age were 300 gm and 6 months respectively. Animals were housed individually with a free access to food and water. In accordance to national and institutional guidelines, 12 light/dark cycle was kept and by help of air conditions, temperature was kept $25^{\circ}$ C. This research study was approved by Research and Ethics Committee, Quality Assurance Unit, Faculty of Medicine, Tanta University, Egypt.

Experimental design:

Rats were divided into four groups $(\mathrm{n}=10)$. Control $(\mathrm{C})$ group, received $0.5 \%$ methylcellulose by oral gavage daily for 90 days. $40 \mathrm{mg}$ dose (40D), $30 \mathrm{mg}$ dose (30D) and $10 \mathrm{mg}$ dose (10D) groups received $40 \mathrm{mg} / \mathrm{kg}$ b.w., $30 \mathrm{mg} / \mathrm{kg}$ b.w., $10 \mathrm{mg} / \mathrm{kg}$ b.w. of AMP by oral gavage daily for 90 days (Figure 1). Rats total body weight is recorded thrice weekly using a digital scale-Tor Rey LEQ 5/10 (Tor Rey, EQ-4HP, Torrey, Mexico City, Mexico).

At the end of study, all rats were sacrificed, samples from blood, testis and epididymis were collected. Testes were examined macroscopically for any alteration of texture, size or color. Testicular and epididymal weights were recorded. The somatic indices for testes and epididymides were calculated by multiplying the sum of division [ organ weight by body weight ] per 100 (9):

Samples of right testis were homoginozed in homogenization buffer (PBS) $(1: 5, \mathrm{w} / \mathrm{v})$, and stored at $-80^{\circ} \mathrm{C}$, while those of left testis were preserved in fixative $10 \%$ paraformaldehyde solution at room temperature.

Sperm count and morphology:

The caudal end of epididymis was cut by scissor and the content was evacuated in a petri dish containing Dulbecco's Modified Eagle Medium F-12 (DMEM-F12) with 10 \% PBS. The suspension was centrifuged at three thousand revolutions per minute for five minutes. The supernatant was mixed with trypan blue (1:1) then spread on Thoma slide for sperm counting using Leica DM100 LED Monocular Microscope (LabX ß), Canada). Three spreads for each sample were examined under light microscope (X20) and 200 sperms were counted, examined and classified as normal headed, pin headed, flattened headed, headless sperms, detached head, bent neck, bent tail (10)

Biochemical analysis:

Blood samples were centrifuged at three thousand revolutions per minute for thirty minutes at $-5^{\circ} \mathrm{C}$. Separated plasma was preserved at $-30^{\circ} \mathrm{C}$. Using commercial kits (SunRed, China), plasma cholesterol, testosterone, luteinizing hormone ( $\mathrm{LH})$, follicle-stimulating hormone (FSH), gonadotropin-releasing hormone ( $\mathrm{GnRH})$ and inhibin B (INHB) hormone were quantified in accordance to manufacturer protocols. Testicular samples (right testis) were used to detect reduced glutathione (GSH), malondialdehyde (MDA), total antioxidant status (TAS) and total oxidant status (TOS) by using commercial enzyme-linked immunosorbent assay (ELISA) (SunRed, China) in accordance to manufacturer protocols.

Histopathological examination:

Hematoxylin and eosin staining was done in accordance to (11). briefly, fresh testis tissue sample was cut into $1 \mathrm{~cm}^{3}$ cubes immediately after extraction from the rats. It was placed in fixative $10 \%$ paraformaldehyde solution and left for 48 hours then placed in tissue processing cassettes. By help of ascending grades of alcohol, tissue is dehydrated to remove water and formalin traces from tissue then immersed in xylene to remove alcohol and facilitate paraffin wax infiltration into the tissue. Cassettes were placed on warm plates 
then tissue was removed and immersed in paraffine blocks. After paraffine solidification, the blocks were cut into $5 \mu \mathrm{m}$ thick sections by using manually operated rotary microtome CUT 4050 (4050F, R) (Microtec Laborgeräte GMBH, Germany). Tissue sections were placed on glass microscope slides, rehydrated, stained with hematoxylin (stains nuclei in blue) for 10 minutes and eosin (stains cytoplasm in red) for 10 seconds. The stained tissue sections were dehydrated again by ascending grades of alcohol for 10 minutes than covered by coverslip. To assess changes in the basement membrane (BM), Periodic Acid Schiff (PAS) staining was done in accordance to (12) using PAS-Stain Kit (ab150680) (Abcam, United Kingdom). Histopathological examinations were performed by two expert histopathologists blinded to our study. Scoring was done in accordance to modified Johnson scoring method (13) (Table 1)

Immunohistochemistry examinations:

Immunohistochemistry was done in accordance to (14). Briefly, paraffine embedded tissue sections were sliced $(5 \mu \mathrm{m}$ thick) and mounted to charged slides. Sections were deparaffinized and rehydrated by descending grades of alcohol. Endogenous peroxidase activity was quenched by placing the tissue sections in $3 \%$ hydrogen peroxide for 10 minutes. $200 \mu \mathrm{l}$ of diluted 1ry antibody [ for Proliferating cell nuclear antigen (PCNA), PCNA Antibody (PC10), dilution 1:2000 and for Terminal deoxynucleotidyl transferase dUTP nick end labeling (TUNEL), TUNEL Assay Kit - HRP-DAB (ab206386), dilution 1:1000] were mounted to the tissue after dilution with antibody diluent as per manufacturer protocol (Signal stain diluent). Slides were incubated overnight at $4^{\circ} \mathrm{C}$ in a humidified chamber. In next morning, slides were washed by wash buffer for 3 minutes then covered with 2 drops of Signal Stain Boost Detection Reagent followed by incubation

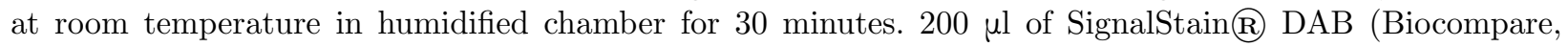
USA) were applied to each section. After staining, slides were immersed in distilled water then counterstained with hematoxylin to stain nuclei in blue for better visualization. Coverslips were applied, examinations were performed by to expert histopathologists blinded to our study. The PCNA index was calculated for each seminiferous tubule by dividing the number of PCNA positive cells (detected by their nuclear brown discoloration) by the total number of germ cells, while the apoptotic index was calculated by dividing the number of TUNEL positive tubule (detected by the presence three or more apoptotic cells) by total number of seminiferous tubules.

Statistical analysis:

Statistical Package for Social Sciences (SPSS) software, 20 V. (SPSS Inc., USA) was used for data analysis. The statistical significance of differences between groups was validated using one-way analysis of variance (ANOVA). Post hoc Tukey-Kramer test was used for groups comparison. Data were expressed in mean \pm standard deviation and probability value was considered significant if $<0.05$.

\section{Results}

At the end of study, body weights of C-group were non-significantly ( $\mathrm{p}>0.05)$ increased $(2.3 \%)$ in comparison to the first day of study, that of 40D, 30D and 10D groups were non-significantly ( $>>0.05$ ) decreased; 1.9 , 1.5 and $3.2 \%$ respectively if compared to the fist day of study. likewise, the testicular weights were nonsignificantly ( $>>0.05$ ) changed in AMP treated groups if compared to C-group (Figure 2).

Sperm counts were significantly $(\mathrm{p}<0.05)$ decreased in AMP treated groups if compared to C-group. There was non-significant $(\mathrm{p}>0.05)$ difference between AMP treated groups. As per sperm morphological abnormalities, there was a significant $(\mathrm{p}<0.05)$ increase in flattened headed sperms in 40D-group if compared to C-group (figure 3).

Plasma cholesterol levels significantly $(\mathrm{p}<0.05)$ decreased in 40D and 30D groups in a dose dependent manner if compared to C-group. Plasma testosterone levels non-significantly ( $p>0.05)$ decreased in AMP treated groups if compared to C-group. Plasma LH, GnRH and INHB levels were significantly $(\mathrm{p}<0.05)$ increased in 40D and 30D groups if compared to C-group. Plasma FSH levels were significantly $(\mathrm{p}<0.05)$ increased in AMP treated groups if compared to C-group. Plasma and testicular tissue GSH and TAS levels were significantly $(\mathrm{p}<0.05)$ decreased in a dose dependent manner in AMP treated groups. Plasma 
and testicular tissue MDA and TOS levels were significantly $(\mathrm{p}<0.05)$ increased in AMP groups in a dose dependent manner. There was a dramatic change in these parameters in 40D-group (Table 2).

Histopathological examination of testicular tissue stained with Hematoxylin and eosin staining showed normal histological architecture with normal spermatogenic cells and tubules with normal BM in C-group. In 40D-group (score 8.2), there was a decrease in spermatogenic cells number with vacuolations of germinal epithelium and BM irregularities. In 30D-group (score 6.8), immature cells were observed with BM irregularities. In 10D-group (score 6.7), vacuolations of germinal epithelium were noticed with regular BM. Score of seminiferous tubules was significantly $(\mathrm{p}<0.05)$ decreased in AMP treated groups if compared to C-group (figure 4,5,6).

PCNA positive cells were determined in seminiferous tubules by the brown discoloration of their nuclei in AMP treated groups. The proliferative index was significantly $(\mathrm{p}<0.05)$ decreased in AMP treated groups if compared to C-group (figure 6,7). TUNEL positive cells appeared with brown discolored nuclei in AMP groups. The apoptotic index was significantly $(\mathrm{p}>0.05)$ increased in these groups if compared to C-group (figure 6,8).

\section{Discussion}

To determine the toxic effect of AMP on the reproductive system; spermatic morphology, parameters of both oxidative stress \& apoptosis and changes of total body \& testicular weights were assessed. In the present study, body weight of all AMP treated groups were decreased minimally at its end if compared with its value at the beginning of the study with insignificant in the testicular weight between AMP treated groups. Zhang et al., (15) reported that AMP administration for thirty days $(30 \mathrm{mg} / \mathrm{kg}$ b.w.) to Kunming mice caused a reduction of total body and testicular weights. Devan et al., (16) also reported that, administration of AMP to Wistar rats $(110 \mathrm{mg} / \mathrm{kg}$ b.w.) caused a reduction of testicular weight which comes in consistent with Chawseen et al., (17) who reported a change in testosterone level and diameter of seminiferous tubules upon adding AMP $(20 \mathrm{mg} / \mathrm{ml})$ to drinking water of albino rats for one month while Rasgele (18) has demonstrated that AMP at a dose ranging from 0.6 to $2.5 \mu \mathrm{g} / \mathrm{ml}$ has no effect on sperm morphology in the first forty-eight hours after administration to Mus musculus mice.

Kong et al., (19) study showed that AMP administration (10-30 mg/kg b.w.) to Sprague Dawley rats caused an increase and decrease in the plasma L.H and testosterone levels respectively. Mosbah et al., (20) reported that AMP administration to Wistar rats for forty-five days at a dose $30 \mathrm{mg} / \mathrm{kg} \mathrm{b}$.w. caused an increase and a decrease in total body and testicular weights respectively with reduction of total sperm count, sperm motility and plasma testosterone levels which comes in consistent with the findings of the present study which presented a dose dependent manner changes due to the effect of AMP on Leydig cells causing a decrease in plasma testosterone levels. As Orta et al., (21) reported that testosterone is mainly synthesized from cholesterol, Eacker et al., (22) stated that there was a link between plasma cholesterol and testosterone levels.

In the present study, upon evaluation of plasma levels of GnRH, FSH, LH and INHB hormones [essential for proper testicular functions and spermatogenesis as Holdcraft \& Braun stated (23)]. The present study showed that AMP administration affect these hormonal balances which could be used as a clinical indicator for infertility as reported by Kumanov et al., (24) in the form of an increased level of plasma FSH \& LH and decrease of plasma levels of testosterone \& INHB. In the present study, total spermatic count decreased in AMP treated groups while the increase in plasma FSH \& LH were noticed to be the lowest in 40D-group. Although there was an increase in plasma INHB (in 30D-group and 10D-group) associated with a decrease in its plasma level in 40D-group. Gasmi et al., (25) reported that AMP administration could be associated with oxidative stress in livre, kidney and central nervous system resulting in Deoxyribonucleic acid damage and apoptosis which finally play a crucial role in the impairment of spermatogenesis with a decrease of total spermatic count, motility and morphological disturbance. Turner \& Lysiak (26) reported that oxidative stress can lead to testicular dysfunction and infertility. Chainy et al., (27) also stated that reactive oxygen species production in the testis is linked to impaired spermatogenesis through lipid peroxidation pathway. 
In the present study, AMP administration was found to induce a reduction of GSH and increase in TOS in both testicular tissue and plasma. The disruption of these parameters was more prominent in testicular tissue than plasma which could be reflected in the form of increased ROS production in testicular cells in accordance to Zaidi et al., (28). As Li et al. (29) stated that oxidative stress is linked to apoptosis, so AMP induced oxidative stress may cause a decrease in total sperm count and increase in total abnormal sperm count. The decreased level of plasma testosterone noticed in our study may interferes with the antioxidant effect of circulating testosterone (30) which may augment the oxidative potential of AMP. Given that apoptosis is associated with pathological condition in many body organ (31) and the testis (32), in the present work, the increase in TUNEL positive cells count and apoptotic index in the testicular tissue may be a result of AMP associated oxidative stress.

The results of the present study demonstrated that, upon histopathological examination of testicular tissue, there was an increase in number of apoptotic cells in the seminiferous tubules and a decrease in spermatogenic cells number with vacuolations of germinal epithelium and BM irregularities of AMP treated groups which increased in a dose dependent manner which comes in consistent with Rachid et al., (33) who reported that administration of AMP (30 mg/kg b.w.) to Wistar rats caused degeneration of testicular germinal epithelium. According to Jain et al., (34), AMP administration to Swiss albino rats in a dose $2.3 \mathrm{mg} / \mathrm{kg}$ b.w. for three months caused spermatogonia degeneration with seminiferous tubules occlusion. The present study showed that, the proliferation index decreased mainly in 40D-group as shown in immunohistochemistry results.

\section{Conclusions}

In summary, AMP oral administration in a dose $10-40 \mathrm{mg} / \mathrm{kg}$ b.w. to male albino Wistar rats was found to possess an oxidative stress and apoptotic impact on the reproductive system which could be reflected on the occupational health precautions. Further studies are recommended to be done to reveal the molecular mechanism of AMP induced toxicity on the male reproductive system.

\section{Competing interests disclaimer:}

Author has declared that no competing interests exist. The products used for this research are commonly and predominantly use products in our area of research and country. There is absolutely no conflict of interest between the author and producers of the products because we do not intend to use these products as an avenue for any litigation but for the advancement of knowledge. Also, the research was not funded by the producing company rather it was funded by personal efforts of the author.

\section{References}

1- Kushwaha N, Mohan A, Bhikane AU. Accidental acetamiprid poisoning in a buffalo. Iran J Vet Res. 19(4):318-320(2018).

2- Levchenko MA, Silivanova EA; Ruzilya Khusanovna Bikinyaeva and Galina Fedorovna Balabanova. Efficacy of acetamiprid and fipronil fly baits against the housefly (Musca domestica L.) under laboratory conditions. Vet World. 11(7):953-958(2018).

3- Mondal S, Pradhan S, Mukhopadhayay SK. Alteration in behavior of rat after chronic exposure to acetamiprid. Vet World. 12(2):254-257(2019).

4- Fang Q, Zu Q, Hua X, et al. Quantitative Determination of Acetamiprid in Pollen Based on a Sensitive Enzyme-Linked Immunosorbent Assay. Molecules. 24(7):1265(2019).

5- Liu G, Zhang R, Li L, et al. Anti-Agglomeration Behavior and Sensing Assay of Chlorsulfuron Based on Acetamiprid-Gold Nanoparticles. Nanomaterials (Basel). 8(7):499(2018).

6- Terayama H, Endo H, Tsukamoto H, et al. Acetamiprid Accumulates in Different Amounts in Murine Brain Regions. Int J Environ Res Public Health. 13(10):937(2016).

7- Jactel H, Verheggen F, Thiéry D, et al. Alternatives to neonicotinoids. Environ Int. 129:423-429(2019). 
8- Wang C, Chen D, Wang Q, Wang Q. Aptamer-based Resonance Light Scattering for Sensitive Detection of Acetamiprid. Anal Sci. 32(7):757-762(2016).

9- Ashafa AO, Orekoya LO, Yakubu MT. Toxicity profile of ethanolic extract of Azadirachta indica stem bark in male Wistar rats. Asian Pac J Trop Biomed. 2(10):811-817(2012).

10- Gatimel N, Moreau J, Parinaud J, Léandri RD. Sperm morphology: assessment, pathophysiology, clinical relevance, and state of the art in 2017. Andrology. 5(5):845-862(2017).

11- Jörundsson E, Lumsden JH, Jacobs RM. Rapid staining techniques in cytopathology: a review and comparison of modified protocols for hematoxylin and eosin, Papanicolaou and Romanowsky stains. Vet Clin Pathol. 28(3):100-108(1999).

12- Tabatabaei Shafiei M, Carvajal Gonczi CM, Rahman MS, East A, François J, Darlington PJ. Detecting glycogen in peripheral blood mononuclear cells with periodic acid schiff staining. J Vis Exp. (94):52199(2014).

13- Manson JM, Zolna LE, Kang YJ, Johnson CM. Effects of cefonicid and other cephalosporin antibiotics on male sexual development in rats. Antimicrob Agents Chemother. 31(7):991-997(1987).

14- Torlakovic EE, Nielsen S, Vyberg M, Taylor CR. Getting controls under control: the time is now for immunohistochemistry. J Clin Pathol. 68(11):879-882(2015).

15-Zhang, J. et al. Oxidative Stress: Role in Acetamiprid-Induced Impairment of the Male Mice Reproductive System. Agr Sci China. 10, 786-796 (2011).

16-Devan, R. K. S., Mishra, A., Prabu, P. C., Mandal, T. K. \& Panchapakesan, S. Sub-Chronic Oral Toxicity of Acetamiprid in Wistar Rats. Toxicol Environ Chem. 97, 1236-52 (2015).

17-Chawseen, M. A. Effects Of Acetamiprid and Glyphosate Pesticides on Testis and Serum Testosterone Level in Male Mice. Journal of Duhok University. 14, 299-306 (2011).

18-Rasgele, P. Abnormal Sperm Morphology in Mouse Germ Cells after Short-Term Exposures to Acetamiprid, Propineb, and Their Mixture. Arh Hig Rada Toksikol. 65, 47-56 (2014).

19-Kong, D. et al. Acetamiprid Inhibits Testosterone Synthesis by Affecting the Mitochondrial Function and Cytoplasmic Adenosine Triphosphate Production in Rat Leydig Cells. Biol Reprod. 96, 254-265 (2016).

20-Mosbah, R., Djerrou, Z. \& Mantovani, A. Protective Effect of Nigella Sativa Oil against Acetamiprid Induced Reproductive Toxicity in Male Rats. Drug Chem Toxicol. 41, 206-212 (2018).

21-Orta Yilmaz, B., Korkut, A. \& Erkan, M. Sodium Fluoride Disrupts Testosterone Biosynthesis by Affecting the Steroidogenic Pathway in TM3 Leydig Cells. Chemosphere. 212, 447-455 (2018).

22-Eacker, S. M. et al. Hormonal Regulation of Testicular Steroid and Cholesterol Homeostasis. Mol Endocrinol. 22, 623-35 (2008).

23-Holdcraft, R. W. \& Braun, R. E. Hormonal Regulation of Spermatogenesis. Int J Androl. 27, 335-342 (2004).

24-Kumanov, P., Nandipati, K., Tomova, A. \& Agarwal, A. Inhibin B Is A Better Marker of Spermatogenesis than Other Hormones in the Evaluation of Male Factor Infertility. Fertil Steril. 86, 332-38 (2006).

25-Gasmi, S. et al. Alteration of Membrane Integrity and Respiratory Function of Brain Mitochondria in the Rats Chronically Exposed to A Low Dose of Acetamiprid. ESPR. 24, 22258-22264 (2017).

26-Turner, T. T. \& Lysiak, J. J. Oxidative Stress: A Common Factor in Testicular Dysfunction. J Androl. 29, 488-498 (2008).

27-Chainy, G. B. N., Samantaray, S. \& Samanta, L. Testosterone-Induced Changes in Testicular Antioxidant System. Andrologia. 29, 343-349 (2009). 
28-Zaidi, S. K., Shen, W. J. \& Azhar, S. Impact of Aging on Steroid Hormone Biosynthesis and Secretion. Open Longev Sci. 6, 1-30 (2012).

29-Li, Y. et al. Characterization of Prohibitins in Male Reproductive System and Their Expression under Oxidative Stress. J Urol. 195, 1160-67 (2016).

30-Vasconsuelo, A., Pronsato, L., Ronda, A. C., Boland, R. \& Milanesi, L. (2011). Role of 17ß-estradiol and testosterone in apoptosis. Steroids. 76, 1223-1231 (2011).

31. Favaloro, B., Allocati, N., Graziano, V., Di Ilio, C. \& De Laurenzi, V. Role of Apoptosis in Disease. Aging. 4, 330-49 (2012).

32. Boekelheide, K., Fleming, S. L., Johnson, K. J., Patel, S. R. \& Schoenfeld, H. A. Role of Sertoli Cells in Injury-Associated Testicular Germ Cell Apoptosis. Proc Soc Exp Biol Med. 225, 105-115 (2008).

33-Rachid, M., Ibrahim, Y. M. \& Aziez, C. Nigella Sativa Oil Protects against Reproductive Toxicity of Acetamiprid Insecticide in Male Rats. Toxicol Lett. 221, S218 (2013).

34-Jain, S. K. Studies on Genotoxicity and Immunotoxicity of Acetamiprid - A Pyridyl Methylamine Neonicotinoid Insecticide in Mice. Thesis-PhD, Lala Lajpat Rai University of Veterinary \& Animal Sciences (2015).

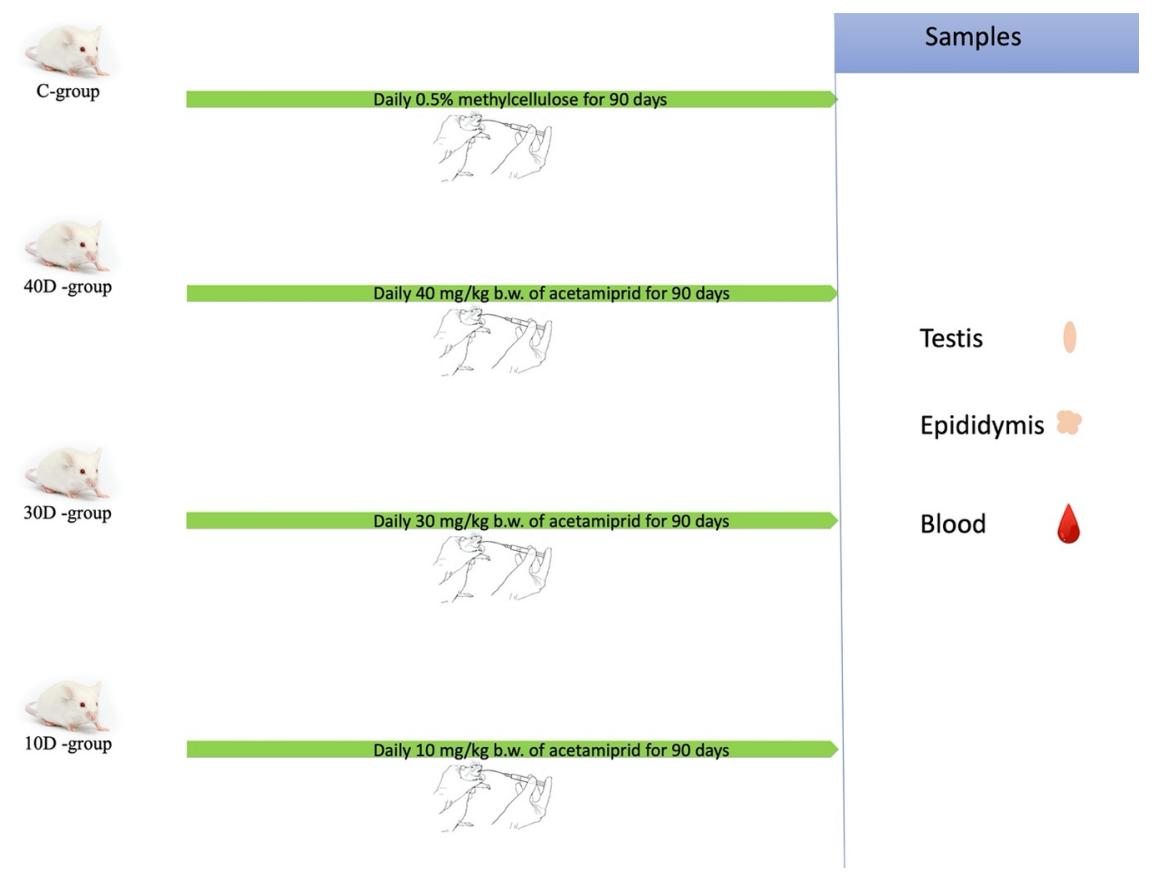

Fig. 1: Schematic representative of experimental design. Rats were divided into four groups. Control group. $40 \mathrm{mg}$ dose, $30 \mathrm{mg}$ dose and $10 \mathrm{mg}$ dose groups received $40 \mathrm{mg} / \mathrm{kg}$ b.w., $30 \mathrm{mg} / \mathrm{kg}$ b.w., $10 \mathrm{mg} / \mathrm{kg}$ b.w. of AMP by oral gavage daily for 90 days. At the end of study, blood, testes and epididymides samples were collected. 


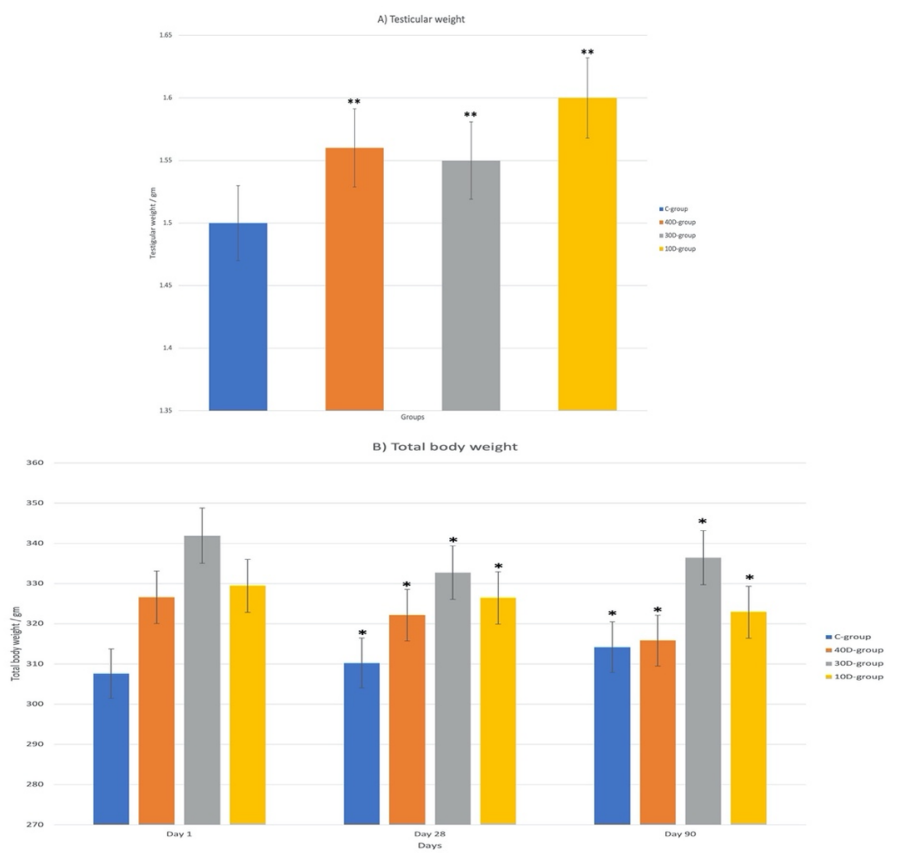

Fig. 2: Effect of AMP (administered orally) on rats' testicular (A) and total body (B) weights. * nonsignificant difference $(\mathrm{p}>0.05)$ in comparison with first day of study. ${ }^{* *}$ non-significant difference $(\mathrm{p}>0.05)$ in comparison with C-group. Data are presented as mean \pm standard deviation.

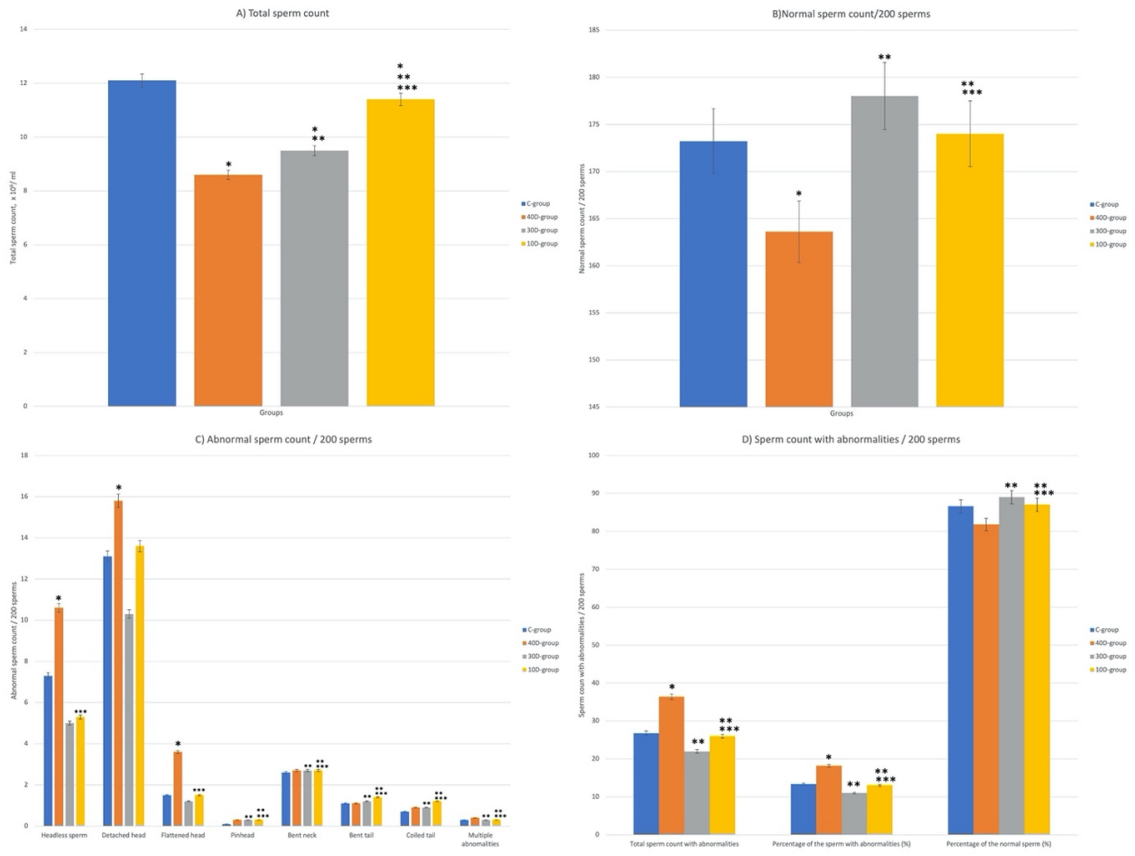

Fig. 3: Effect of AMP (administered orally) on rats' total sperm count (A), normal sperm count / 200 sperms (B), abnormal sperm count / 200 sperms (C) and sperm count with abnormalities / 200 sperms $(\mathrm{D}) .{ }^{*}$ significant $(\mathrm{p}<0.05)$ difference in comparison to C-group. ${ }^{* *}$ non-significant $(\mathrm{p}>0.05)$ difference in 
comparison to 40D-group. ${ }^{* * *}$ non-significant $(\mathrm{p}>0.05)$ difference in comparison to 30D-group. Data are presented as mean \pm standard deviation.
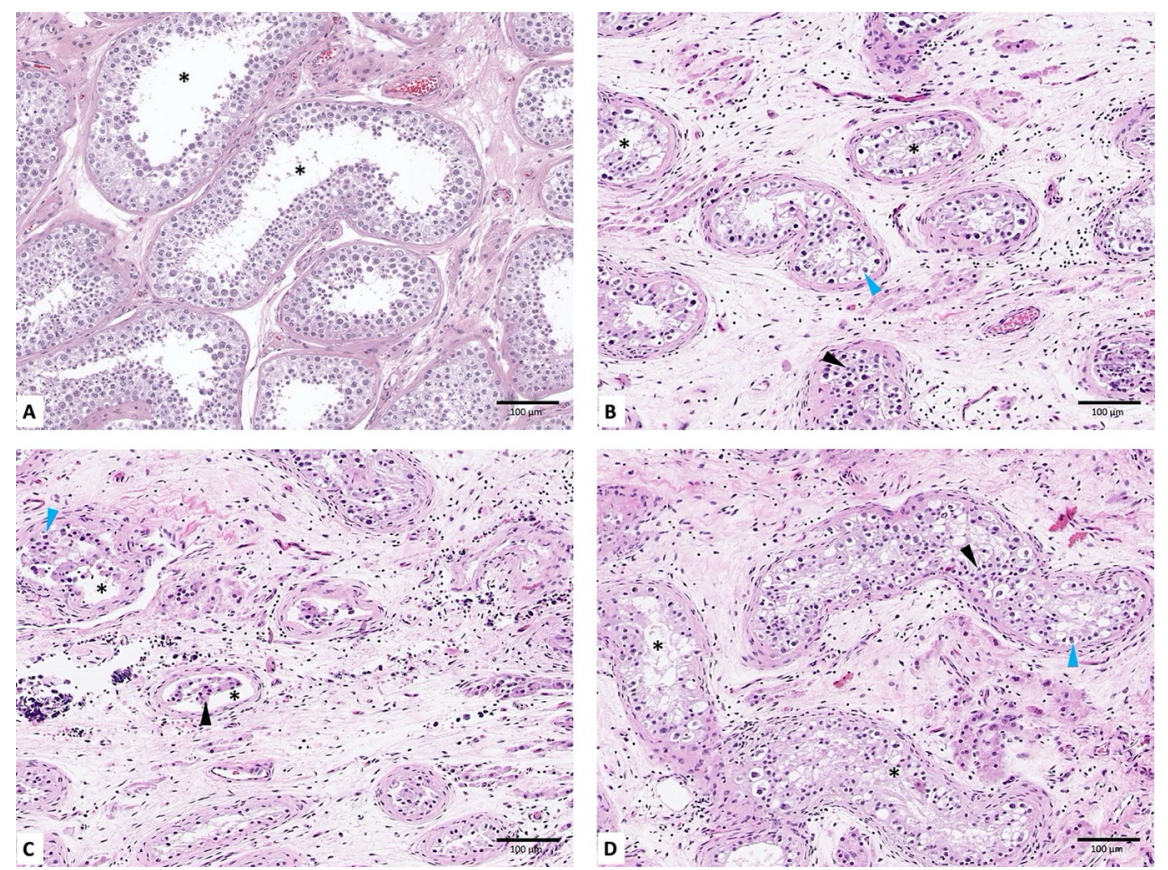

Fig. 4: Photomicrograph of rat testis stained with hematoxylin and eosin (X 1000). (A) C-group shows normal histological architecture with normal spermatogenic cells and normal basement membrane. (B) 40Dgroup shows a decrease in spermatogenic cells number with vacuolations of germinal epithelium and basement membrane irregularities. (C) 30D-group shows immature cells with basement membrane irregularities. (D) 10D-group shows vacuolations of germinal epithelium with regular basement membrane. Note: seminiferous tubules $(*)$, vacuolation (blue arrow) and immature cells (black arrow). 


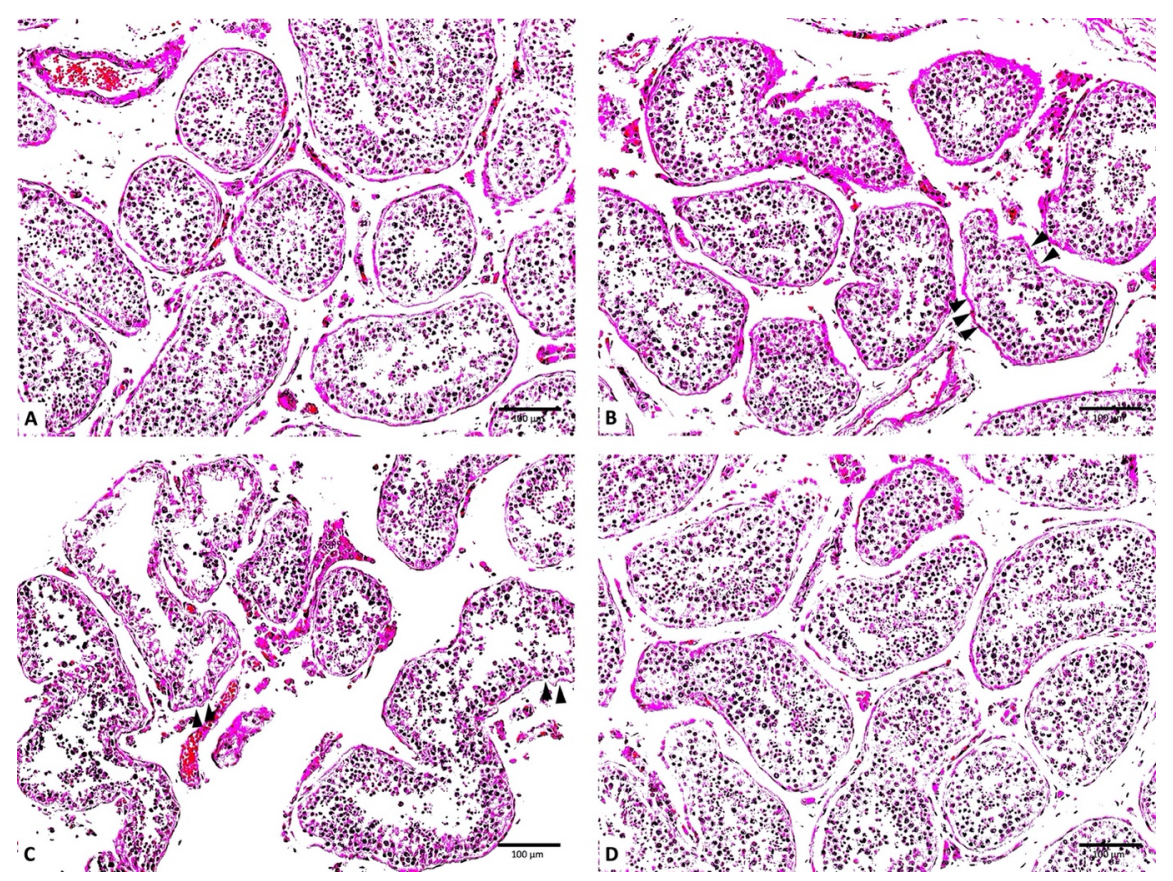

Fig. 5: Photomicrograph of rat testis stained with Periodic acid-Schiff (X 1000). (A) and (D) represents C-group and 10D-group respectively which shows regular basement membrane. (B) and (C) represents 40D-group and 30D-group respectively shows basement membrane irregularities. Note: basement membrane irregularities (black arrow).

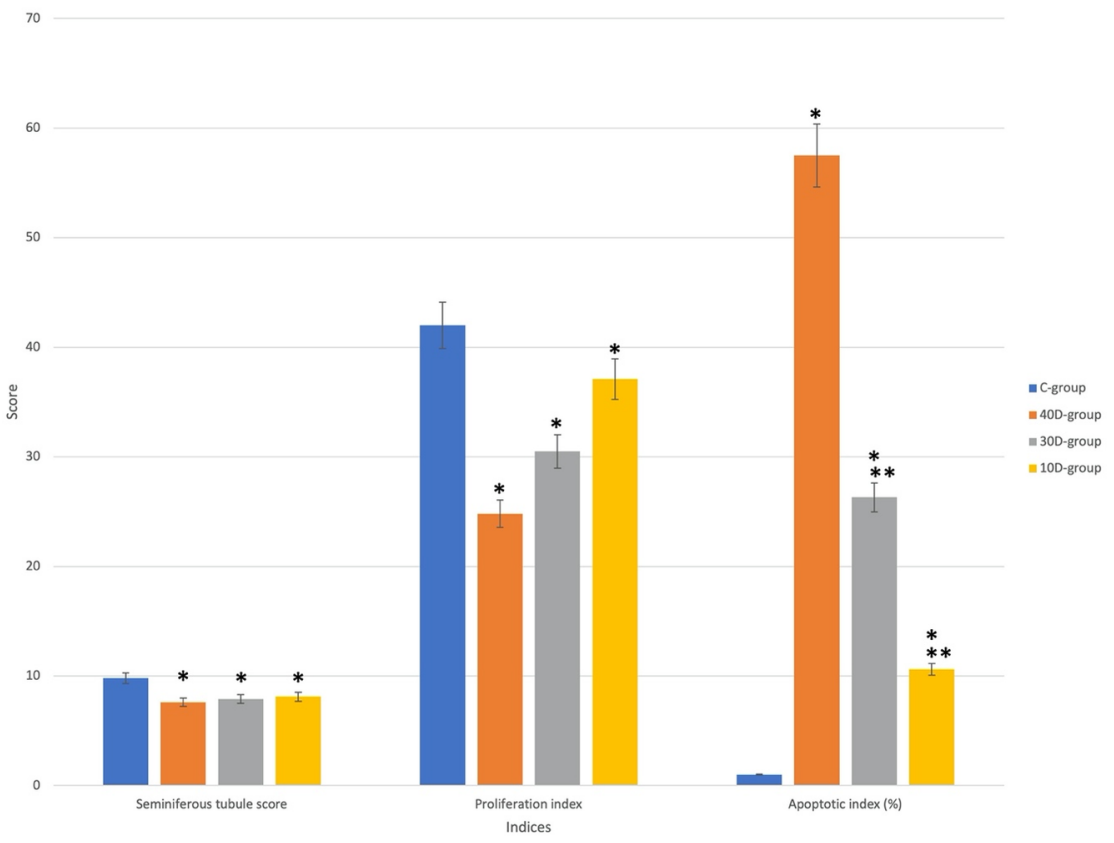

Fig. 6: Effect of AMP (administered orally) on rats' testis seminiferous tubule histopathological score in addition to proliferative and apoptotic indices. ${ }^{*}$ significant $(\mathrm{p}<0.05)$ difference in comparison to C-group. 
** significant $(\mathrm{p}<0.05)$ difference in comparison to 40D-group. Data are presented as mean \pm standard deviation.
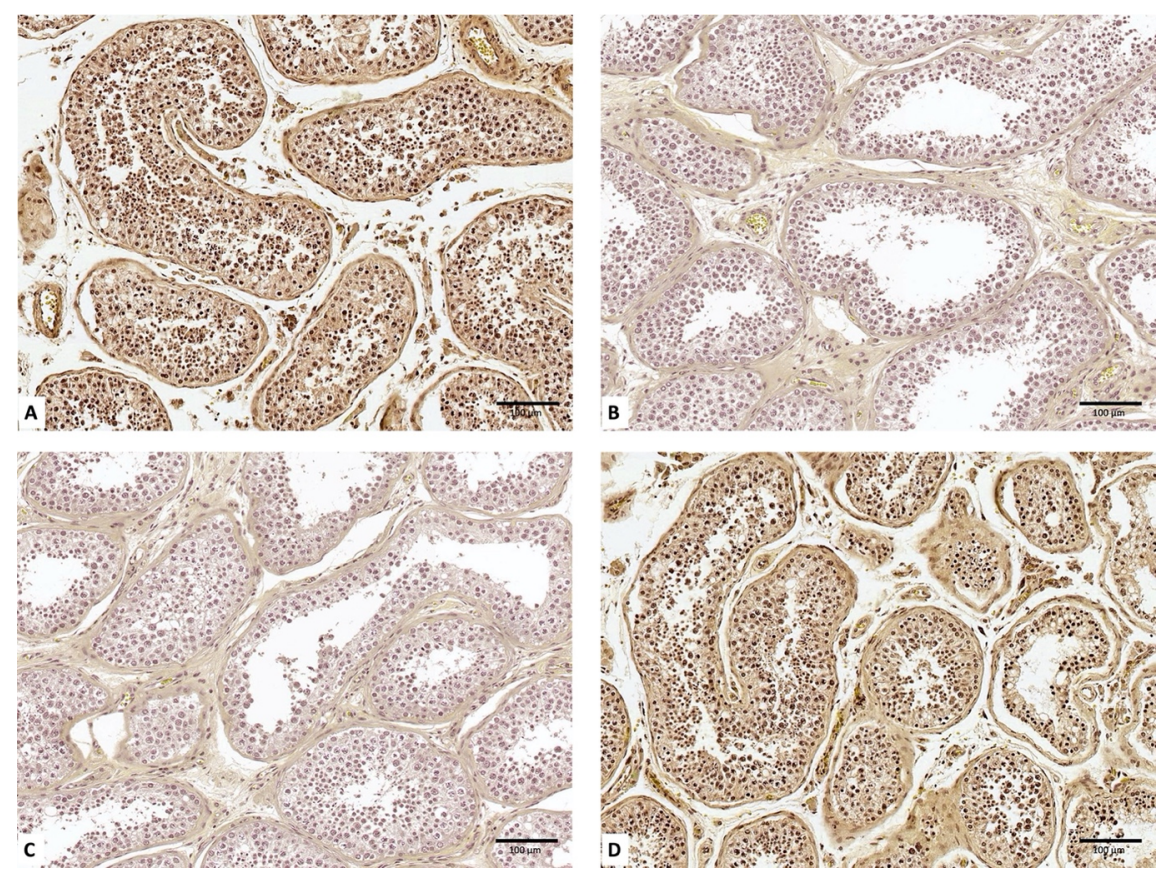

Fig. 7: Photomicrograph of rat testis stained with PCNA (X 1000). (A) and (D) represents C-group and 10D-group respectively which shows numerous PCNA positive cells. (B) and (C) represents 40D-group and 30D-group respectively shows few PCNA positive cells.
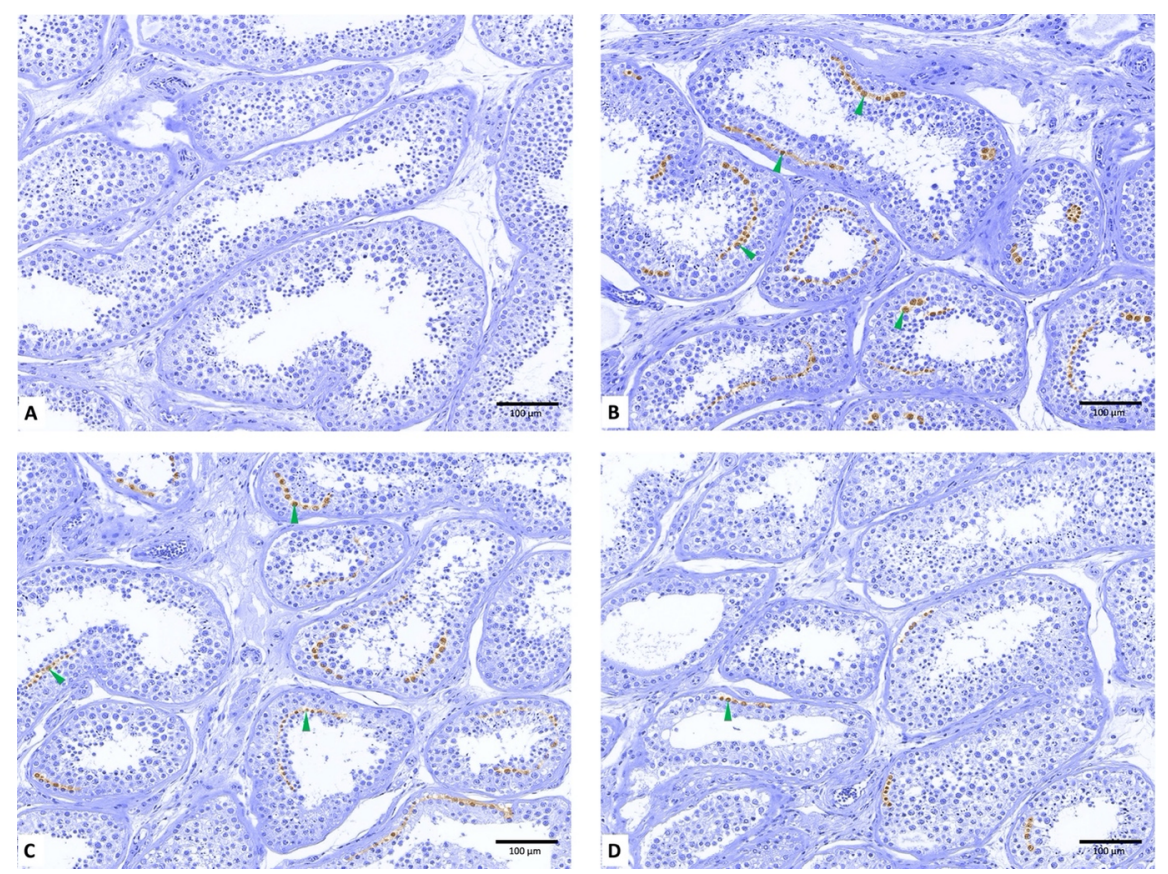

Fig. 8: Photomicrograph of rat testis stained with TUNEL (X 1000). (A) and (D) represents C-group 
and 10D-group respectively which shows few TUNEL positive cells (green arrow). (B) and (C) represents 40D-group and 30D-group respectively shows numerous TUNEL positive cells (green arrow).

\begin{tabular}{ll}
\hline Histopathological Findings & Score \\
\hline No tubular lining epithelium & 1 \\
No germinal cells & 2 \\
Spermatogonia only & 3 \\
No spermatozoa, No spermatids, Few spermatocytes & 4 \\
No spermatozoa, No spermatids, Many spermatocytes & 5 \\
No spermatozoa, No late spermatids, Few early spermatids & 6 \\
No spermatozoa, No late spermatids, Many early spermatids & 7 \\
Tubule with1- 4 spermatozoa, Few late spermatids & 8 \\
Impaired spermatogenesis, Many late spermatids & 9 \\
Full spermatogenesis & 10 \\
\hline
\end{tabular}

Table 1: Modified Johnson scoring method used for histopathological scoring

\begin{tabular}{|c|c|c|c|c|c|}
\hline & Parameters & C-group & 40D-group & 30D-group & 10D-group \\
\hline \multirow[t]{9}{*}{ Plasma } & $\begin{array}{l}\text { Testosterone } \\
(\mathrm{ng} / \mathrm{mL})\end{array}$ & $3.43 \pm 0.34$ & $2.63 \pm 0.28^{* *}$ & $2.76 \pm 0.29^{* *}$ & $2.91 \pm 0.50^{* *}$ \\
\hline & $\mathrm{LH}(\mathrm{mIU} / \mathrm{mL})$ & $22.18 \pm 0.68$ & $22.97 \pm 0.31^{*}$ & $24.24 \pm 0.28^{*}$ & $23.76 \pm 0.69$ \\
\hline & $\mathrm{FSH}(\mathrm{IU} / \mathrm{L})$ & $8.20 \pm 0.67$ & $22.41 \pm 0.33^{*}$ & $25.38 \pm 0.72^{*}$ & $22.98 \pm 0.49^{*}$ \\
\hline & GnRH (ng/L) & $205.89 \pm 22.99$ & $311.78 \pm 9.03^{*}$ & $310.956 \pm 0.06^{*}$ & $318.83 \pm 8.50$ \\
\hline & INHB (ng/mL) & $9.36 \pm 0.39$ & $8.46 \pm 0.64^{*}$ & $21.181 \pm 0.41^{*}$ & $10.29 \pm 0.27$ \\
\hline & $\begin{array}{l}\text { Cholesterol } \\
(\mathrm{mmol} / \mathrm{L})\end{array}$ & $6.57 \pm 0.64$ & $5.31 \pm 0.37^{*}$ & $5.40 \pm 0.46^{*}$ & $5.91 \pm 0.45$ \\
\hline & $\begin{array}{l}\text { MDA (ng/mg } \\
\text { protein) }\end{array}$ & $1.67 \pm 0.12$ & $2.57 \pm 0.17^{*}$ & $2.14 \pm 0.12^{*}$ & $1.93 \pm 0.113^{*}$ \\
\hline & TAS $(\mathrm{U} / \mathrm{mL})$ & $45.78 \pm 3.21$ & $21.35 \pm 0.93^{*}$ & $25.34 \pm 0.76^{*}$ & $27.59 \pm 0.89^{*}$ \\
\hline & TOS $(\mathrm{nmol} / \mathrm{mL})$ & $3.84 \pm 0.37$ & $4.79 \pm 0.21^{*}$ & $3.08 \pm 0.23^{*}$ & $3.93 \pm 0.10^{*}$ \\
\hline \multirow[t]{4}{*}{ Testicular tissue } & $\begin{array}{l}\mathrm{GSH}(\mathrm{mmol} / \mathrm{mg} \\
\text { protein) }\end{array}$ & $3.48 \pm 0.117$ & $2.63 \pm 0.14^{*}$ & $2.79 \pm 0.13^{*}$ & $2.01 \pm 0.23^{*}$ \\
\hline & $\begin{array}{l}\text { MDA (ng/mg } \\
\text { protein) }\end{array}$ & $7.68 \pm 0.57$ & $22.41 \pm 0.63^{*}$ & $10.92 \pm 2.118^{*}$ & $7.98 \pm 0.51^{*}$ \\
\hline & $\begin{array}{l}\text { TAS }(\mathrm{U} / \mathrm{mL} \text { per } \\
\text { g protein) }\end{array}$ & $57.64 \pm 2.72$ & $41.65 \pm 2.37^{*}$ & $49.14 \pm 2.39^{*}$ & $50.74 \pm 2.37^{*}$ \\
\hline & $\begin{array}{l}\text { TOS }(\mathrm{nmol} / \mathrm{mL} \\
\text { per g protein) }\end{array}$ & $23.99 \pm 0.14$ & $25.04 \pm 0.31^{*}$ & $24.84 \pm 0.33^{*}$ & $24.39 \pm 0.53^{*}$ \\
\hline
\end{tabular}

Table 2: plasma hormonal levels, plasma and testicular tissue oxidative stress parameters after AMP administration to albino Wistar rats. ${ }^{*}$ significant $(\mathrm{p}<0.05)$ difference in comparison to C-group. ${ }^{* *}$ non-significant $(\mathrm{p}<0.05)$ difference in comparison to $\mathrm{C}$-group. Data are presented as mean \pm standard deviation. 